\title{
VARIANTES TEXTUALES SORPRENDENTES EN LAS COMEDIAS DE LA SEXTA PARTE DE CALDERÓN
}

\author{
José María Viña Liste \\ Departamento de Filología Española \\ Facultad de Filología \\ GIC-Universidad de Santiago de Compostela \\ Burgo de las Naciones \\ 15771 Santiago de Compostela. España \\ josemaria.vina@usc.es
}

[Anuario calderoniano (ISSN: 1888-8046), 4, 2011, pp. 365-391]

Todo trabajo de índole ecdótica está orientado a la búsqueda de la lección verdadera de un texto para ofrecerlo con la máxima autenticidad y corrección a sus destinatarios, es decir, depurado de elementos ajenos a la voluntad de su autor, pero también le es exigible que indague el proceso por el que una palabra, si era la lección primitiva, pudo dar lugar a otras alteradas o distintas. Para los efectos que aquí interesan - mejor que los modelos aristotélicos ya codificados desde hace siglos, por adiectio, detractatio, transmutatio e inmutatio- he considerado conveniente establecer los siguientes 7 tipos: lugares críticos 
que implican una lectura descuidada del antígrafo manuscrito, ya fuese éste claro (tipo 1), ya presumiblemente con escritura dudosa (2), ya confuso (3); casos en que se realizó una lectura descuidada de un antígrafo impreso que debía de estar claro (4); simplificación de una lectura más o menos complicada para quien transcribe el texto, lo que equivale a la tipificada banalización o lectio facilior (5); copia - ya de un manuscrito, ya de un impreso- realizada al dictado que, incorrectamente entendido, se trascribe con segmentación verbal errónea (6) y, por último, erratas de imprenta (7).

La verdad es que uno acaba por encontrarse con un buen acervo de sorpresas entre los indefectibles y esperables errores de transmisión textual, no pocos de los cuales capaces de suscitar la distensión del estudioso al depararle ocasiones de hilaridad provocando en él una sonrisa, que no deja de funcionar como cierta legítima y muy humana compensación a los dilatados afanes vertidos durante días y años en la rigurosa, exigente, oscura y adusta tarea de la edición crítica.

Con el fin de no perderse entre el poblado bosque de especies encontradas, además de hacer una drástica selección de las variantes halladas para exponer solo medio centenar de lugares críticos, conviene establecer una sencilla tipología de las mismas. Así, se empezará por presentar las que más abundan, en número de 31, hasta alcanzar 62 por ciento de los casos: las fundadas en la lectura descuidada de un antígrafo manuscrito, ya sea éste tan claro como los confeccionados por profesionales expertos (tipo 1,13 casos), ya presumiblemente dudoso (tipo 2, 9), o con seguridad confuso (tipo 3, 9). Luego se examinarán las que derivan de un antígrafo impreso que era muy claro (tipo $4,7)$ pero que fue de nuevo transcrito con escasa atención. Se pasará luego a las que proceden de una lectura simplificada por el copista (tipo 5, 4), con tendencia a caer en la trampa de realizar lectiones faciliores. Se verán finalmente las que parecen proceder de copias realizadas al dictado (tipo 6,5), sea desde una fuente manuscrita o impresa, que con frecuencia redundan en errores generados por alteración de las fronteras entre palabras consecutivas. Tampoco se omitirá, a título de ejemplo y para concluir, la mención de alguna variante que puede no haber sido ni más ni menos que errata imputable al tipógrafo (tipo 7, 2). En cada uno de los siete apartados correspondientes se irán presentando los pertinentes textos de las comedias, cuando los 
haya, en la secuencia correlativa con que los ofreció Vera en 1683, que es también la adoptada para la edición de la Biblioteca Castro ${ }^{1}$.

1. Aunque el testimonio Typ que nos sirve de base para la edición de Andrómeda sea el más fiable, ello no quiere decir que esté exento por completo de errores, por lo que nos hemos visto en la necesidad de realizar en él al menos 33 enmiendas.

1.1. Sirviéndonos de su partitura de la parte musical, debe corregirse en Andrómeda el adjetivo que en el texto para los actores aparece como «feroz» con «veloz», que es lo que conviene al báratro o infierno, que rompa veloz - no feroz - sus propias entrañas para favorecer sin demora con su fuego volcánico los designios de Discordia. En este caso no se puede excluir la posibilidad de que un colaborador no inculto del copista le hubiese dictado el pasaje pronunciando la consonante ' $v$ ', no como fricativa sonora bilabial sino con punto de articulación labiodental haciéndola confusa con la 'f' de carácter sordo ${ }^{2}$.

1.2. Polídites solicita a Libio en Andrómeda que prepare un ambiente de lujo adecuado para recibir a Dánae, infanta "del Piro", lo que no debe interpretarse como especializada en fugarse o evadirse, de acuerdo con el caló y la expresión 'darse el piro', sino que la errada variante de Typ debe enmendarse mediante la lectura común de $\mathrm{E}$ y VT con «una infanta de Epiro» ${ }^{3}$.

1.3. El texto de El José depara una buena decena de extraños lugares críticos.

M incluye 324 variantes válidas así como 285 versos adicionales también aceptables; omite 135 versos que sí están en E y VT; pero el ms. M, que hemos adoptado como testimonio base, parece represen-

${ }^{1}$ Los cincuenta lugares críticos seleccionados (cuya cantidad se incluye entre paréntesis) tienen la siguiente procedencia, según se ve en la tabla final: 1 (8) Andrómeda y Perseo, 2 (10) El José de las mujeres, 3 (3) Los empeños de un acaso, 4 (1) Primero soy yo, 5 (4) La estatua de Prometeo, 6 (4) El secreto a voces, 7 (1) Dar tiempo al tiempo, 8 (5) El mágico prodigioso, 9 (6) Mejor está que estaba, 10 (1) Fieras afemina amor, 11 (4) Dicha $y$ desdicha del nombre, 12 (3) Para vencer a amor, querer vencerle.

${ }^{2}$ Alcina y Blecua, $1975, \$ 2.5 .2 .4$ y 2.5.4.

${ }^{3}$ Maestre [M] con del Epiro enmienda mal y hace el verso hipermétrico. 
tar la rama más próxima y fiel al original, por declaración expresa del copista, Sebastián de Alarcón, aunque su labor esté fechada el año siguiente al $\mathrm{HSA}^{4}$, menos correcto. E y VT derivan de otra rama distinta, más descuidada y además abreviada, a pesar de los versos añadidos. Tanto el testimonio neoyorquino HSA como el lisboeta L nos han brindado ciertas variantes válidas para realizar leves enmiendas.

Parece error del tipo que se trata en esta sección la confusión del copista de $\mathrm{M}$ al atribuir como adjetivo latino, por lo demás mal declinado, «inmundo» a «idolum», donde la lectura correcta de E y VT es «idolum in mundo».

1.4. Para La estatua de Prometeo en la 3. ${ }^{a}$ jornada del manuscrito base de la BHM se ofrece un verso hipermétrico compartido por tres personajes en este pasaje:
MerLín
Está bien.
Aparta y cómo lo enmiendo verás: Devina...
LIBIA ... Pandora.
MerLín Pandorga.
LiBIA Gentil enmienda, por cierto.

Vera, que lee «Pandorra» por «Pandorga», advierte la hipermetría y trata de arreglarla modificando el verso siguiente así: «Bien lo haces, cierto». Pero para depurarla basta omitir la intervención de Libia que, por error del copista, interrumpe por segunda vez la de Merlín, dejando así el diálogo en el que éste insiste en su alterada y jocosa pronunciación del nombre de la Eva mitológica helena como Pandorga:

${ }^{4}$ HSA parece proceder de un volumen facticio. La Jornada $1^{a}$ ocupa 23 hojas y unos 1046 vv.; otro copista, con mejor letra, escribe la Jornada $2^{a}$, de 14 hojas y unos 980 vv., y la $3^{\text {a }}$, de 12 hojas y unos 800 vv. El total de sus versos es 2826 , menos de lo habitual. Pudo haber sido hecho para uso de compañía y, aunque con leves alteraciones censoriales no coincidentes con las de $\mathrm{M}$, no hay demasiadas correcciones de mano ajena. Acota peor que $\mathrm{M}$, con quien se complementa bien para enmendar algunos errores y omisiones. 
MERLín

LiBIA
Está bien.

Aparta y cómo lo enmiendo verás: Devina Pandorga...

1.5. Siete años más tarde, en 1677 , las descuidadas y desautorizadas ediciones de la Quinta parte, cuyo responsable debía de estar exento de mucho bagaje tanto relativo a geografia como a mitología, al transcribir un verso de su erudito antígrafo donde se tenía que leer «Etna, Volcán, Mongivelo, Vesubio», yerran así de disparatadas: "en bolcan mongibelo nube subio»

1.6. Curiosos errores comunes en $E l$ secreto, trasmitidos a todos los demás testimonios desde una copia intermedia del autógrafo, son «culto» por «loco», y "corrompida la vena» por «corrompida la 'o' en 'a'». El resultado de nuestra labor nos lleva a postular la existencia de un apógrafo perdido, muy próximo al autógrafo en el tiempo, que muy bien pudo haber sido un apunte teatral para la primera compañía que lo llevase a las tablas, del que derivarían, con posibles intermediarios desconocidos, los demás testimonios que han llegado a nuestro conocimiento.

Vamos a detenernos en un caso paradigmático en donde la corrupción de un verso, por error de copia realizada en la parte más alta del stemma, no solo hace que el pasaje resulte incomprensible y hasta absurdo, sino que deriva en la posterior alteración en mayor o menor grado de dos de los siguientes tres versos que cierran la frase en que se encuentra.

Cuando uno lee por primera vez en su vida y en una comedia de Calderón la expresión "corrompida la vena» lo que de inmediato le viene a la mente es la asociación semántica con la septicemia con sus esperables y desagradables secuelas de la gangrena purulenta, y enseguida piensa cerciorarse de ello consultando a un médico o a un veterinario acerca de a qué tipo de enfermedad, humana o animal, pueda aludirse; luego, con calma y tratando de reducir tan dramática situación, pasa a relacionarla con el idiotismo o frase coloquial «pudrirse la sangre", significativo de 'disgustarse o enfadarse hasta impacientarse o exasperarse' (DRAE, sub voce 'sangre'). Pero, la verdad es que Calderón nunca quiso expresar nada parecido a eso. 
En otros lugares ${ }^{5}$ ya me he ocupado de esos cuatro versos de $E l$ secreto que, escritos originalmente por el poeta con absoluta adecuación semántica y total coherencia gramatical, aunque no sin alguna autocorrección a manera de los pentimenti pictóricos, fueron mal leídos por un copista en 1668, ya erróneamente teniendo a la vista el autógrafo, ya - lo más probable- en un apógrafo muy próximo, alterado o confuso.

Con ciertas vacilaciones y correcciones, pues, pero muy puntilloso en el uso de las comillas, en 1642 Calderón escribe en la jornada tercera de A, su autógrafo, "que corronpida la .o. en .a.», así, con sendas vocales flanqueadas por puntos equivalentes a nuestras comillas simples, como se hacía con los números romanos en los códices medievales («en su compaña .LX. pendones»). Transcribo el pasaje final del diálogo en romance entre el gracioso Fabio y su amo Federico, primer galán:

Hoy que tengo más que hablar, ¿ocasión he de tener de hablar menos? Eso no, que será piedad cruel dejar pudrir un secreto que a nadie sirva después; que, corrompida la «o» en «a» - como dijo el cordobésde secreto, hecho secreta, huela mal y no haga bien.

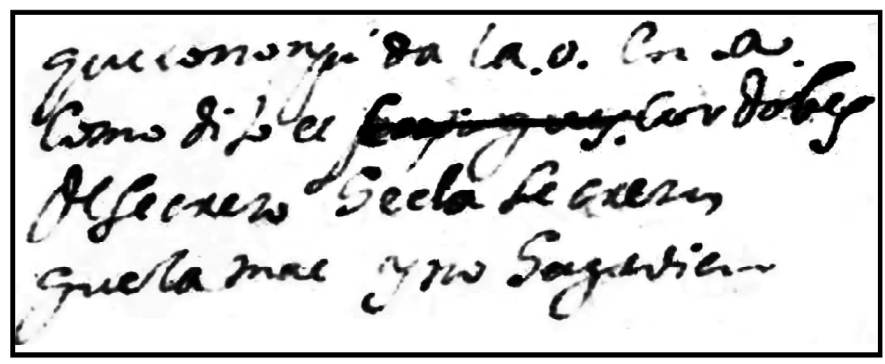

${ }^{5}$ Viña Liste, 2010 y 2011, en prensa. 
La transcripción literal del tetrástico afectado es ésta:

\author{
que corronpida la «o» en «a» \\ como dijo el cordobes \\ de secreto hecho secreta \\ guela mal y no haga bien
}

El error fundamental arranca de un copista próximo al autógrafo, cuyo trabajo no ha llegado de modo directo hasta nosotros, que lee con descuido cuatro palabras que Calderón escribió muy claras:

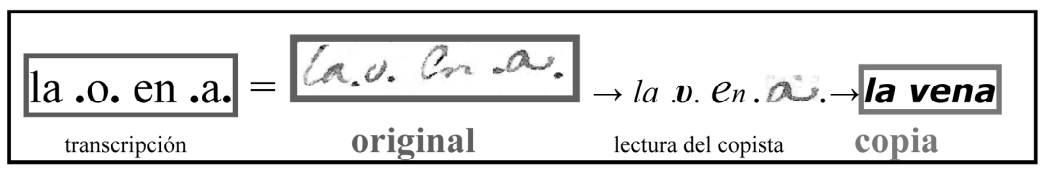

Pues bien, la transmisión de errores se prolonga en el tiempo, pasando por García de la Huerta y Hartzenbusch ${ }^{6}$, quien en parte copia a su antecedente, hasta llegar a la solución ecléctica de Valbuena Briones que, sin llegar al logro de hacer inteligible el pasaje, taracea así:

Que corrompida la vena, como dijo el cordobés, del secreto, hecha secreta, huele mal y no hace bien.

1.7. A partir de una lectura diáfana en el autógrafo de El secreto en que Fabio se refiere a sí mismo como «tú» — «has sido tú endemoniado»-, si se entiende como aparte, todos los testimonios se arman un lío de mil demonios; Diferentes es el más disparatado con «has sido tú, entender no, ni a do", pero también lo son en menor grado HSA con "el diablo se lo ha contado", Viena - el menos errado, aunque con esforzado ops ingenii- con «sería su endemoniado» y Vera con «el demonio lo ha contado».

${ }^{6}$ Hartzenbusch reproduce el texto de Vera, con puntuación casi correcta: «Que corrompida la vena, / Como dijo el cordobés / Del secreto, hecha secreta, / Huele mal y no hace bien». 
1.8-11. Los errores de mayor bulto en El mágico enmendados con el autógrafo —un poco confuso aquí en su escritura- son: «albergue» corregido por «oh, llegue» y "paciencia» por «apariencia»; se trata de errores comunes conjuntivos entre Escogidas y Vera, en donde éste lee mal porque copia de aquél, que también lee mal. En esta comedia Justina desea que se

\section{desvanezca la apariencia}

de la noche con el día.

Pues bien, por error derivado de una mala lectura de la palabra «apariencia», Escogidas, y con ella Vera, la convierten en otra parecida, «paciencia», que rima igualmente con la precedente «licencia». A esta enmienda hay que añadir «verdad» corregida con «beldad» — posible resultado de un dictado poco claro-, "puesto» con "puerto» - con lecturas correctas comunes entre el manuscrito y Vera, que ahí acierta-, además de "dudo» con «duro", que Vera también detecta, pero corrige mal ope ingenii con «agudo» donde lo correcto es que Cipriano diga:

No ociosamente en mi mano esté aqueste acero duro.

Por lo demás Vera interpreta mal lo que en el manuscrito era «UNOS Dentro» —abreviado por Escogidas con «Den.»— como «Dem.», abreviatura de 'demonio'.

1.12. Para Mejor está, además del final distinto, hay unas 205 variantes significativas entre E y VT, sin contar las no sustanciales que en su mayoría afectan a las acotaciones ${ }^{7}$.

Es muy probable que se haya deslizado una errata — simple pero justificable- en la impresión de Escogidas al emplear dos veces en versos consecutivos la palabra "causa», cuando lo correcto en la segunda

${ }^{7}$ Valbuena Briones añade, aportándolas como es habitual de Hartzenbusch, tan donosas variantes como esta en la que hace decir al anciano don César de Mejor está: «Estoy de oficio dos veces», en lugar de la correcta declaración: «Es hoy mi oficio dos veces». 
ocurrencia es «casa». En efecto, los demás testimonios hacen declarar bien al galán Carlos:

\section{La causa de no temer esa casa, es porque tengo noticia della, y sabré della escaparme más presto.}

1.13. Yerra Escogidas en Mejor está, copiando mal de su antígrafo manuscrito al transformar una conjunción — «pues»- en verbo («puedes»), con lo que además crea una hipermetría: «No, pues no se ha de saber» pasa a ser «No puedes, no se ha de saber».

2.14. Donde en Andrómeda E y VT ${ }^{8}$ leen correctamente "vestiglo», que tiene el significado de 'monstruo horrible, animal fiero', el ms. Typ, cuyo antígrafo es, si no el original, un apógrafo muy próximo a él, yerra - tal vez por desconocimiento de la palabra - con «bestigio» escrito con 'b', con valor de 'indicio, señal, huella'; pero tampoco es imposible que su copista hubiera confundido en su antígrafo ms. (donde la palabra pudo escribirse con su etimológica 'b') la 'l' con una vocal 'i'.

2.15. Es probable, aunque no necesario, que la palabra 'epiciclo' tuviese su segunda 'c' más cerrada que la primera en el antígrafo de Typ para Andrómeda, por lo que su copista interpretó la palabra como 'epicielo' en una curiosa formación neológica puesta en boca de Perseo dirigiéndose a Palas. El error, subsanado ya en E, es explicable con facilidad pues el héroe no se atreve a pedir a la diosa que descienda a su tierra abatiendo el vuelo desde su alto solio que trasciende el orbe de los humanos, es decir desde su divina morada celestial.

2.16. Dialogan Andrómeda y los Ecos en el siguiente lugar crítico, que debe editarse así, enmendando Typ con E:

${ }^{8}$ VT edita bien vestiglo en el texto de la comedia, pero en su intrascendente fe de erratas previa se corrige - mal- en vestigio. 
¿Qué más puede ser que sea

mi infelice desventura?

Ecos

Ventura.

ANDRÓMEDA

Segunda vez, ladrón eco, la primer sílaba usurpas de mi última razón...

Tal lectura es perfecta por cuanto que los ecos, como ladrones, roban, se quedan o suprimen la primera sílaba de la última palabra que acaba de pronunciar la protagonista - 'des-ventura'-, repitiendo o devolviendo tan solo 'ventura', al igual que poco antes lo habían hecho con 'alg-una' despojándola de sus tres primeros fonemas hasta dejarla en 'una', los tres últimos. Yerran en cambio Typ — que, si no tiene el original como antígrafo, presumiblemente dudoso o corregido en este verso, se sirve de un apógrafo muy próximo al mismoyVT con "postrer sílaba»; no menos que $\mathrm{H}$ y Valbuena innovando con «postrer palabra», e incluso $\mathrm{M}$ a sus huellas, con "postrar sílaba», añadiendo errata en el adjetivo.

2.17. En El José, al reprochar Eleno a Capricho que lo acose como a cristiano, lo hace bien en L y VT empleando estas palabras: "Que eres apóstata nota». En cambio E lee ahí disparatadamente "¿Quieres apóstata, mora?», con la misma lectura que HSA, donde un avisado lector advirtió el error y con buena pero desacertada voluntad corrigió mal con «¿Quieres apóstata morir?»?

2.18-19. Transcribimos "excepción», donde el testimonio base de La estatua lee "excepsion», y los demás, ante una palabra que debió de resultarles extraña por infrecuente, «exencion», «exempcion» y «essempcion». También unificamos en «disfraz» las tres lecturas discrepantes del manuscrito: «disfraz», «dizfraz» y «dizfrás».

2.20-21. Flérida, refiriéndose a Federico en El secreto, mantiene «que él tiene libertad y harta», lo que Cosmerovio en Viena, sin duda leyendo mal en su desconocido antígrafo el verbo «tiene» y alterándolo en «tiempo», acaba por corregir así: «que el tiempo libertad harta le da».

${ }^{9} \mathrm{M}$ omite aquí 4 versos por homoioteleuton. 
O fue errata de imprenta de Escogidas o, ya la copia que llegó a ella, ya su desconocido antígrafo manuscrito, no debían de estar muy claros cuando edita que Flora rompió las puertas de la «tierra», como si creara volcanes, donde los demás testimonios leen algo más verosímil:

$$
\begin{aligned}
& \text { y así, falseando las guardas, } \\
& \text { rompí a esta torre las puertas. }
\end{aligned}
$$

2.22. En Fieras afemina la lectura «Divina esfera» de la suelta, de la que se genera hipermetría - ya detectada pero no corregida como errónea por Wilson-, seguida por las Quintas, y que Vera —al que secundan tanto el manuscrito tardío BNE 15.581 como Hartzenbusch - para reducir el verso a endecasílabo corrige con «Sacra esfera», hay que enmendarla y obtener el endecasílabo correcto, mediante el ms. BNE 17.031, con «Di: una esfera», palabras con las que Hércules impide que Licas reitere el sustantivo 'palacio' y magnifica el esplendor del mismo.

Es probable que la suelta, desde donde surge la alteración, tuviese como antígrafo el propio original, que ofrecería aquí una lectura poco clara o tal vez corregida. Bastaría la hipótesis de un fenómeno no infrecuente en los manuscritos, que la vocal 'u' estuviera muy aproximada a la 'i' y trazada con forma angulosa similar a la 'v', para explicarse la alteración de "Di una» en «Divina», máxime si el contexto favorece la confusión al situarnos en un ámbito de divinidades mitológicas. He aquí el pasaje afectado, a cuya luz puede comprenderse mejor todo el complicado proceso:

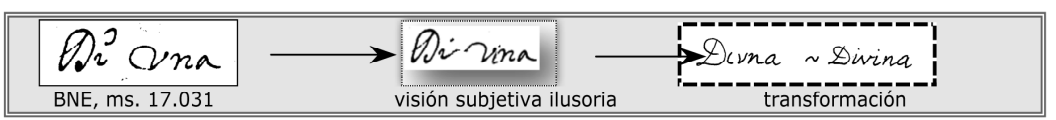

HÉRCULES

LICAS

HÉrCUles

LICAS
No es para ti esa plática.

Pues sea,

ya que el monte permite que se vea allí un rico palacio, plática para mí...

$$
\text { ¿Qué? }
$$

... que en su espacio 
a Euristio le esperemos

más a placer.

HérCUles

LICAS

HÉRCULES

LiCAS
No dices mal; lleguemos, que sin duda, pues es donde llamado vengo de él, será donde aposentado la conferencia nuestra entablar quiera.

Ya de aquí se descubre...

Corriose el foro del bosque $y$ descubriose la fachada de un palacio ricamente adornado de jaspes y bronces, y como dicen los versos, coronada de un pensil, cuyas hojas eran doradas $y$ sus frutas de oro.

en cuya arquitectura

se unieron la riqueza y la hermosura!

¡Qué fábrica tan bella!...

3.23. Pudo tener un antígrafo ms. algo confuso el responsable de la copia Typ de Andrómeda cuando transcribe las palabras de Perseo, como si estuviera descifrando un mágico signo, por «Mas, jay, que al poso me sale Medusa!», leyendo "paso» como «poso».

3.24-27. Es probable que en El José tanto E como VT, muy próximo descendiente suyo, hayan leído mal de un antígrafo manuscrito confuso o deturpado en su escritura, lo que lleva a ambos a editar, atribuyendo el superlativo al encanto de una dama, «vilísimo» por «bellísimo", correcta lectura de M y HSA. El mismo fenómeno tiene lugar cuando aquéllos acotan "Dentro las Gitanas", que no tienen cabida alguna en el reparto de la comedia, por "Dentro guitarras», a las que sí se oye sonar. Confusos eran también los antígrafos de HSA como para haber leído «memaba dilo» y de E que lee «me mata. dilo», donde M y VT, éste ope ingenii, editan "me maravillo», expresión del asceta Eleno en vista de la suma diligencia de que parece dar pruebas Capricho, el gracioso. También crearon problemas para copistas e impresores en el lugar crítico en que Eleno disuade a Eugenia de que se entregue a la muerte exponiéndose a perder el mérito del martirio por no hacerlo en «orden» de la fe, lectio difficilior pero aceptable de M 
—aunque escriba «horden»—, donde con más fácil solución de lo confuso tanto HSA como E y VT leen «odio» y L «honra».

3.28. Hay un pasaje en El mágico que resulta muy enrevesado, lo mismo en los testimonios antiguos que en las ediciones modernas. Simplifico aquí el problema: Calderón escribe en su autógrafo "ollegue» para "oh, llegue» sin suficiente separación entre ambas palabras; de ahí, de esa lectura confusa, derivan alteraciones de posibles apógrafos que cristalizan en Escogidas y Vera como «alvergue» - es decir, «albergue»— y confunden todavía más a los editores que los siguen. En mi propuesta, donde Lisandro se identifica como natural de Roma,

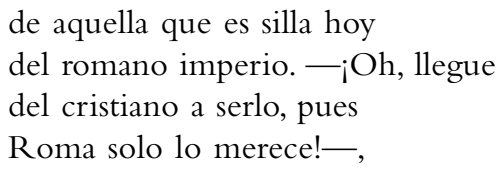

el sentido desiderativo expresado por las palabras del anciano queda claro: que Roma llegue a ser sede del imperio cristiano, pues solo ella merece serlo.

3.29-30. En el caso de Dicha y desdicha del nombre hay enmiendas aceptadas de Escogidas - a quien siguen los demás testimonios- para errores exclusivos del manuscrito base, el 14806 de BNE, por ejemplo «estemos» para «extremos». Recurriendo a Vera se enmiendan unos treinta errores comunes a los dos testimonios mencionados antes, por ejemplo, «fiestas» con «sustos».

Donde sus testimonios más antiguos reproducen bien las palabras del criado Fabio

que si a vejeces de amor

procuro echar un remiendo

la deficiente copia del ms. BNE 17156, altera el primer verso en "que si careces de amor"; se trata de una copia hecha por dos amanuenses que tiene muchas correcciones y tachaduras.

3.31. El mismo manuscrito, que aquí parece revelarse como hecho precipitadamente al dictado, hace decir también a Fabio que 
... en términos monetarios,

hicieran buen aquel libro

donde los demás testimonios leen correctos «equilibrio».

3.32. A otra criada, Flora, el mismo copista, horro de gran bagaje mariológico ni geográfico, le atribuye este disparatado símil:

Fue Anajarte con ella una niña de lorito

confundiendo la alusión a la advocación mariana que tuvo su origen en el santuario de Loreto, sito en Italia no lejos de Ancona, con un ave exótica domesticada ${ }^{10}$.

4.33. Un error de este tipo 4 en El José, que arranca desde Hartzenbusch, esforzado en demasía por facilitar la comprensión de la frase, llega hasta los editores del siglo xx. En efecto, estos leen «si ahora en tu celo discurro» donde los antiguos, correctamente «si había en tus celos discurso".

4.34. En el caso de Los empeños en VT se altera el texto claro y coherente del antígrafo impreso E - por explicable confusión contextual de un tipógrafo desatento que don Juan no llegó a advertirque transforma a unas ninfas "vagando» por unos floridos jardines en seres «bajando» y haciendo compañía a una hermosa dama que con ellas desciende de lo alto. El pasaje de Los empeños donde se altera el gerundio debe editarse así:

${ }^{10}$ Vera Tassis y el ms. BNE 16968, que lo copia, leen bien, «Loreto». El ms. BNE 17156 tal vez lee «del orito», pero también Escogidas, lo mismo que el ms. BNE 14806 al que sigue, yerran aquí con «Lorito». En el verso anterior al deturpado se alude a la temible ferocidad de Anajarte, el personaje mitológico femenino que ya había aparecido en 1652, ocho años antes, en La fiera, el rayo y la piedra, relacionada con el segundo término del título. 


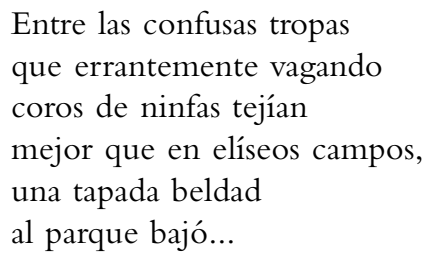

4.35-36. Todas las ediciones que nos han llegado del siglo XVII de Los empeños, incluso VT, con excepción de nuestro testimonio base E, caen en el mismo error de hacer que don Juan, en un curioso reto de dimensiones atléticas, desafie a don Félix a medir su anatomía, sus «espaldas», en lugar de usar el sustantivo correcto referido a las armas, sus "espadas». Ignoro hasta qué punto las tres veces que se mencionan las 'espaldas' a lo largo de la comedia han podido contaminar, reiterándose el error de edición en edición, a estas 'espadas' que aparecen seis veces repetidas.

Lo sorprendente se acrecienta cuando, en alteración quiasmática, de inmediato don Juan en las mismas ediciones se ofrece cortés a guardarle a su rival las «espadas» — así, en un increíble plural—, en lugar de las correctas «espaldas», su integridad corporal.

4.37. Solo Vera en El secreto, enmendando donde no hacía falta al creer que el error estaba, por repetición, en su antígrafo, discrepa de los demás testimonios en los versos memorables de

más flores sin tiempo nacen

que abril produce con tiempo

sustituyendo en el segundo verso «con tiempo» por «contento».

4.38. Uno de los dos copistas de HSA para la primera jornada de Mejor está cae en el burdo error de hacer que Carlos se declare responsable de algo turbio relacionado con «el alción», es decir, no tanto con un astado de gran porte sino con el ave llamada martín pescador, en lugar de con «la acción» reprochable del galán por haber irrumpido en la casa de Flora ${ }^{11}$.

${ }^{11}$ A pesar de que Calderón llegó a usar al menos en seis pasajes teatrales documentados la forma «el» del artículo femenino antepuesto al sustantivo «acción», posi- 
4.39. E es el testimonio más antiguo (1654) de Para vencer; tiene deficiencias, errores y erratas.VT (1683) enmienda casi 80 leves errores y 23 omisiones de E, pero añade otros fallos.

Hay un lugar en esta comedia que, en Escogidas, resultaba claramente legible, aunque no tanto comprensible para sus descendientes; es la expresión que usa el gracioso Espolón, «con capa y haldas en cinta». En la segunda parte del verso — «haldas en cinta»— es donde se genera la confusión que lleva a los testimonios del siglo XVII a sustituir la primera con «los doctos», salvo en el ms. BNE 15614, que altera por su parte más aún: "con caba y asidas encinta». Mi opinión es que se utiliza aquí una locución adverbial coloquial que significa 'corriendo de viaje a toda prisa', 'remangarse la falda o la túnica para poder correr', 'prepararse para hacer algo con urgencia'. No faltan documentos coetáneos que, inspirados en el libro del Éxodo aluden a la vestimenta de los judíos en la Pascua, rememorando su precipitada huida de Egipto ante la inminencia de la plaga de mortandad que producirá el ángel exterminador entre los primogénitos.

5.40. No es imposible que Vera Tassis hubiera conocido un testimonio de Andrómeda que no ha llegado hasta nosotros para enmendar el curioso error que pasó de Typ a E en que éstos leen «... vio / la foca el varado huésped de sus ondas...» donde la lectura correcta es "... vio / la urca el airado huésped de sus ondas...». A pesar de la parcial coincidencia de grafemas entre 'urca' y 'foca' y entre 'airado' y 'varado', se trata de un error muy extraño que tal vez se base en una mala lectura del antígrafo que usó Typ confundiendo la nave o 'urca' con el animal llamado 'orca' y sustituyendo luego como lectio facilior este enorme cetáceo de la familia de los delfines pero mayor que ellos por la más conocida 'foca', además de cambiar 'airado' originariamente atribuido a Cetus, huésped de las ondas marinas, por 'varado' pensando en la nave que zozobra al encallar en el acantilado costero. Se tra-

blemente por tratar de evitar cierto grado de cacofonía, al igual que lo habían hecho Juan Huarte de San Juan en Examen de ingenios (1575-1588) y Pedro J. (1651), el testimonio que seguimos emplea la forma más común de «la acción». 
ta de la única enmienda aceptada de Vera Tassis para esta comedia, pero es decisiva para que resulte inteligible el pasaje donde se alude a Cetus - padre etimológico de todos los cetáceos-, el furioso y temible monstruo marino que hace zozobrar a una gran embarcación mercante denominada 'urca', palabra procedente del neerlandés 'hulk' y adoptada en inglés, que por cierto dará nombre a un horrible héroe del imaginario infantil, por fortuna ya relegados al olvido él y su estética feísta. ¿Sería creíble que una simple foca, por lo demás dotada de inesperadas alas y removiendo piélagos como montañas, se empeñase en la inútil tarea de hundir un navío de gran porte cuando además ya estaba varado?

5.41. Primero soy yo fue la única comedia para la que nos sirvió la edición de Vera como testimonio base, pero no fue del todo inútil su colación con $\mathrm{M}$, el ms $17.448^{22}$ de la BNE del siglo XVII, aunque sólo trasmita la primera jornada y ello con muchas incorrecciones; con todo, ofrece alguna lectura concreta aceptable como enmienda, ya que al menos seis variantes suyas mejoran el texto de Vera.

Selecciono aquí de M la variante «borrén», referida a la almohadilla forrada de cuero bajo el arzón, destinada a proteger el lomo de la montura, para corregir la lectio facilior de VT «barren» — extraña en él, sin duda una errata imputable al impresor que se escapó a la atenta vigilancia de don Juan — inserta en el largo pasaje relatado por Gutierre en romance:

... entre el arzón

y el borrén salió a la espalda

sangriento el hierro, cayendo

por encima de las ancas.

5.42-43. Como simples muestras relevantes de Para vencer, elijo los dos lugares que siguen, ambos enmendados porVT. Escogidas, leyendo mal, con lectura facilior, en su desconocido antígrafo, traduce al español el latinismo del texto correcto escribiendo "non estorbaréis», con lo que deturpa la exigible rima asonante y aproximada con 'a' tónica y 'e', como en el precedente «hablen»:

ESPOLÓN Justo es, por ser mandamiento de Amor el «non estorbabis». 
También altera la lectura de «abrasa» convirtiendo la forma verbal en la incomprensible «atrasa» en los siguientes versos:

logró en todos los venenos

con que abrasa y con que olvida.

6. A veces la errónea segmentación de las palabras en el discurso donde se integran se relaciona estrechamente con la transposición al escrito de lo oído a un lector del antígrafo en el momento de realizar la copia del mismo al dictado, máxime cuando palabras o sintagmas resultan ser poco frecuentes en el habla cotidiana.

6.44. El siguiente caso puede atestiguar que el copista responsable de Typ para Andrómeda hizo al menos este pasaje al dictado de un presunto colaborador; en efecto, cuando Perseo advierte la presencia de Medusa prorrumpe en esta temerosa interrogación más que retórica:

\author{
... ¿Qué hará después \\ de verme, si el hado antes \\ que me vea me ha dejado \\ el ver monstruo semejante?
}

Simplemente ha realizado una segmentación errónea de las sílabas que configuran el adjetivo "helado", confundiéndolo en su resultado con el irresistible destino o inevitable hado fijado por la divinidad.

6.45-46. Típico error que parece dimanar de copia hecha al dictado de un colaborador del amanuense está donde en El José confluyen HSA y L: "ya todo sea acabado» y «ya todo eso sea acabado». La lectura correcta la aporta M, con el que aquí coincide VT: «Ya todo eso se ha acabado».

En un caso similar muy revelador existen indicios de que alguien que seseaba colaboró con el tipógrafo de E, al menos en este lugar en el que Melancia se dirige a una muchedumbre: «vulgo de nobles, jay, plebe!», donde todos los demás testimonios leen bien sin excepción: «vulgo de nobleza y plebe». 
6.47-48. En Mejor está, tras haber apostrofado Carlos al sol, Escogidas así como el manuscrito de HSA con ellas emparentado, editan «si ay luminar», sustituyendo un infinitivo por un sustantivo al fundir la preposición «a» con la vocal inicial del verbo «iluminar», tal vez con apoyo en una asociación semántica en el ámbito sideral; Vera y la suelta de BNE leen bien como "si a iluminar». Es probable que el copista de HSA contase con un colaborador que le dictase su texto. Ello explicaría su chusca y disparatada variante, cuando el galán Fabio, en lugar de "Quereislo vos defender», dialoga con su criado Dinero de esta guisa:

FABIO ¿Queréis lobos defender?

DiNERO Sí quiero, y vuelvo a envidar.

FABIO Pues veamos si podéis.

Sacan las espadas.

7.49. Disparatada y jocosa errata de imprenta — si no estaba ya en su desconocido antígrafo manuscrito- la que se desliza en el texto de El José en E cuando dialogan el asceta y el gracioso:

CAPRICHO Llegad.

ELENO

¿Tú me pretendes?

CAPRICHO

Sí.

Se crea así también un verso hipermétrico, donde la lectura correcta, la que aportan juntos HSA, E y VT, es simplemente «¿Tú me prendes?», sin más improcedentes pretensiones.

7.50. Resumiendo lo observado en Dar tiempo, Escogidas se revela como mejor testimonio; 87 de las 107 variantes (81\%) son aceptables en su lectura, aunque algunas sean adiáforas o equipolentes, mientras que de Vera, quien corrige con «papeles» la evidente errata de imprenta de Escogidas que lee "papales» — probablemente fomentada por la situación, en que se están realizando trámites matrimoniales-, 
pueden ser aceptables 20 variantes. De todas ellas, solo la indicada depara una sorpresa relevante.

En las páginas que preceden puede quedar de manifiesto, o al menos atisbarse, cómo la actividad ecdótica del GIC no se limita al cómodo expediente de elegir y editar el mejor de los testimonios de entre los que han transmitido cada una de las comedias calderonianas integradas en sus Partes - lo cual, por cierto, no sería labor menospreciable como si fuese de escasa entidad y utilidad-, sino en ofrecerlas a la luz pública impresas con transcripción y puntuación acordes con las convenciones actuales más aceptables desde el punto de vista filológico, además de depuradas, en la medida de lo humanamente posible, de cuantos errores, erratas y deficiencias formales se les pudieran haber adherido en el proceso de su difusión desde hace ya casi cuatro siglos.

No dejan de tener cierta gracia, como tantos errores humanos de naturaleza verbal, los equívocos y quid pro quo generados por ciertas variantes de las comedias calderonianas. Se trata de errores humanos de naturaleza verbal, con los que cuantos escriben y publican no pueden sentirse ajenos ni molestos sino comprensivos, por implicados en parejas experiencias, y que por lo demás no tienen mayor trascendencia que la filológica.

Recapitulemos lo más sorprendente de lo que copistas e impresores nos han deparado en la transmisión de la Sexta parte sin negarles para sus inevitables despistes nuestra tolerante sonrisa antes de tirarles la primera piedra: hacer de un temible "vestiglo» un mero "vestigio" indiciario, de unos simples "papeles» unos documentos "papales» con su aura de eclesiales, o del sustantivo «borrén» la forma verbal «barren»; convertir un «epiciclo» en un «epicielo», que suena mucho más celestial, o el gerundio "vagando» en «bajando», o la "desdicha del nombre» en el total abandono o «desecha del hombre»; trastrocar «espadas» en «espaldas» y viceversa, leer «corrompida la vena» en lugar de "corrompida la 'o' en 'a'» y mudar así una alteración vocálica en una desconocida dolencia; tornar a una infanta de "Epiro» en una especialista del "piro», relegar a una temible y magnífica "orca» a la especie de simple e inocente «foca» que suele ser la base de su dieta, trans- 
formar un navío "varado» en la costa marina en "airado huésped» de la misma y "una acción» en «un alción», sea gran cérvido o ágil volátil; solicitar del poder infernal que actúe «feroz», lo que implica la demanda de que ejecute «veloz» su ardiente y cáustico castigo; deturpar hasta tal punto el nombre de "Pandora» que llega a tornarse no solo «Pandorga» sino "Pandorra»; confundir un leve "paso» con un grave «poso»; calificar al «bellísimo» encanto de una dama denostándolo como «vilísimo», confundir unas "guitarras» que suenan a lo lejos con unas parleras "gitanas» tras las bambalinas, o a la virgen «de Loreto» con la "del lorito» o incluso «del orito»; estar dispuesto a defender no solo a otro personaje, sino hasta a unos «lobos» que brillan por su ausencia en la comedia; romper nada menos que las enormes puertas de la «tierra» sin quedar satisfecho con derribar las sólidas de una «torre»; entender el "equilibrio» como «aquel libro», hacer que un hombre - - , por más señas, ermitaño - pregunte a otro que intenta capturarlo si le pretende, sin contentarse con que lo prenda, hacer que "el hado» consiga dejar a uno «helado» al igual que a veces el arte logra helarte, mostrar al primaveral mes de abril «contento» de las flores que "con tiempo" produce o calificar con hipérbole excesiva a un bello y rico palacio como una "divina» o «sacra» esfera...

Una tabla final podrá ser útil para apreciar de modo sinóptico y ordenado cuanto en las páginas anteriores se ha ido exponiendo. Las cifras situadas en ella en la columna de la izquierda como datos entre puntos se refieren la primera al orden del caso expuesto, la segunda a la tipología en que se ha clasificado la variante, y la tercera al número de orden de la comedia en la edición veratassiana de la Sexta parte. 


\section{VARIANTES EN LA SEXTA PARTE}

datos

lecturas correctas

lecturas erradas

1.1.1 veloz

2.1.1 una infanta de Epiro

3.1.2 idolum in mundo

4.1.5 verás: Devina Pandorga...

5.1.5 Etna, Volcán, Mongivelo, Vesubio"

6.1.6 que, corrompida la "o" en "a"

7.1.6 has sido tú cndemoniado

8.1.8 apariencia

9.1.8 beldad

10.1.8 puerto

11.1.8 aqueste acero duro

12.1.9 la causa de no temer esa casa

13.1.9 No, pues no se ha de saber

14.2.1 vestiglo

15.2.1 epiciclo

16.2.1 la primer sílaba usurpas

17.2.2 Que eres apóstata nota

18.2.5 excepción

19.2.5 disfraz

20.2.6 que él tiene libertad harta

21.2.9 rompí a esta torre las puertas

22.2.10 Di: una esfera feroz

una infanta del Piro

idolum inmundo

verás: Devina...

$\begin{array}{ll}\text { Libia } & \text {... Pandora. } \\ \text { MERLín } & \text { Pandorga | Pandorra }\end{array}$

en bolcan mongibelo nube subio

que, corrompida la vena

has sido tú, entender no, ni a do

el diablo se lo ha contado

sería su endemoniado

el demonio lo ha contado

paciencia

verdad

puesto

aqueste acero dudo | aqueste acero

agudo

la causa de no temer esa causa

No puedes, no se ha de saber

bestigio

epicielo

proster sílaba | postrer palabra | postrar sílaba

¿Quieres apóstata, mora? | ¿Quieres apóstata morir?

excepsión | exención | exempción | essempción

dizfraz | dizfrás

que el tiempo libertad harta le da

rompí a esta tierra las puertas

Divina esfera $\mid$ Sacra esfera 
23.3.1 al paso me sale

24.3.2 a su bellísimo encanto

25.3.2 Dentro guitarras

26.3.2 me maravillo

27.3.2 en orden de la fe

28.3.8 oh, lleguc

29.3.11 si a vejeces

30.3.11 Dicha y desdicha del nombre

31.3.11 hicieran buen equilibro

32.3.11 una niña de Loreto

33.4.2 si había en tus celos discurso

34.4.3 errantemente vagando

35.4.3 mediremos las espadas

36.4.3 os guardaré las espaldas

37.4.6 con tiempo

38.4.9 considerando la acción

39.4.12 con capa y haldas en cinta

40.5.1 vio / la urca el airado huésped

41.5.4 entre el arzón y el borrén

42.5.12 de Amor el «non estorbabis»

43.5.12 venenos / con que abrasa y con que olvida

44.6.1 helado antes que me vea me ha dejado

45.6.2 Ya todo eso se ha acabado

46.6.2 vulgo de nobleza y plebe

47.6.9 si a iluminar

48.6.9 Quereislo vos defender

49.7.2 ¿Tí me prendes?

50.7.7 papeles al poso me sale

a su vilísimo encanto

Dentro las Gitanas

memaba dilo | me mata. Dilo

en odio de la fe | en honra de la fe

albcrguc

si careces

Dicha y desecha del hombre

hicieran buen aquel libro

una niña de lorito | una niña del orito

si alıora ens tu celo discurro

errantemente bajando

mediremos las espaldas

os guardaré las espadas

contento

considerando el alción

los doctos haldas en cinta | con caba y asidas encinta

vio / la foca el varado huésped

entre el arzón y el barren

de Amor non estorbaréis

venenos / con que atrasa y con que

olvida

el hado antes que me vea me ha dejado

Ya todo [eso] sea acabado

vulgo de nobleza, iay, plebe!

si [h] ay luminar

Queréis lobos defender

¿Tú me pretendes?

papales 


\section{BibLiOgRAFÍA}

\section{EDICIONES}

Además de las ediciones de todo el teatro de Calderón realizadas desde el siglo XIx (Keil, Hartzenbusch, Astrana / Valbuena Prat / Valbuena Briones), debe destacarse la edición facsímil de las Partes publicadas en el siglo XVII.

Sexta parte de comedias del célebre poeta español don Pedro Calderón de la Barca... que publica... don Juan de Vera Tassis..., Francisco Sanz, Madrid, 1683 [del facsímil del ejemplar de la Universidad de Cambridge Hisp. 5.68.6, ed. por D. W. Cruickshank y J. E. Varey, VT].

Comedias de don Pedro Calderón de la Barca, Juan Eugenio Hartzenbusch, ed., $B A E$, Madrid, Rivadeneyra, 4 tomos, 1848-1850, vols. 7, 9, 12 y 14. [7, 9, 12: 2. ${ }^{a}$ ed. 1851-1856; se usa t. I, Madrid, Impr. de Hernando y Cía., 1901; t. II, Madrid, Rivadeneyra, 1881; t. III, Madrid, Rivadeneyra, 1886; t. IV, Madrid, Hernando, 1899, H].

Pedro Calderón de la Barca, Obras completas, edición, prólogo y notas de Á.Valbuena Briones, Madrid, Aguilar, 1960-1966 [se usa vol. I, 1966 ; vol. II, $\left.1960^{2}, \mathrm{VB}\right]$.

- Comedias, VI. Sexta parte de Comedias, ed. J. M. ${ }^{a}$ Viña Liste, Madrid, Biblioteca Castro, 2010,VL.

\section{Comedias}

En este apartado se hace una selección de las ediciones antiguas y modernas utilizadas.

Se emplean las siguientes siglas y abreviaturas:

BHM: Biblioteca Histórica Municipal [de Madrid], olim BMM: Biblioteca Municipal de Madrid.

BL: British Library, British Museum, London.

BNE: Biblioteca Nacional de España, olim BNM.

HSA: Hispanic Society of America, New York.

De Andrómeda y Perseo.

Testimonio base: Houghton Library, Harvard University, ms. Typ 258 H (ca. 1653). [Typ]

Parte Veinte y una de comedias nuevas escogidas de los mejores ingenios de España, José Fernández de Buendía, a costa de Agustín Vergés, Madrid, 1663 [BNE R 22674,pp. 47-96]. [E]

Maestre, Rafael, ed., Andrómeda y Perseo, Fábula [escénica], edición filológica, crítica y escenotécnica, Almagro, Museo Nacional del Teatro, 1994. [M] 
De El José de las mujeres.

Testimonio base: BNE, ms. 16.548, fechado en 1669, copiado por Sebastián de Alarcón. [M]

HSA, ms. B 2612, Madrid, 1668, 49 hojas. [HSA]

De los mejores el mejor, libro nuevo de comedias varias nunca impressas, compuestas por los mejores ingenios de España, Parte Trece, Mateo Fernández, a costa de Francisco Serrano de Figueroa, Madrid, 1660, pp. 275-311 [BNE R 22666]. [E]

BHM, ms. Tea 1-39-7, fechado en Lisboa 1670, copiado por Jerónimo de Heredia, 60 hojas. [L]

De Los empeños de un acaso.

Testimonio base: El mejor de los mejores libro [sic] que ha salido de comedias nuevas, Alcalá, 1651, pp. 306-347, con el título Los empeños que se ofrecen [BNE 17932] [E].

El mejor de los mejores libros..., María de Quiñones, a costa de Manuel López, Madrid, 1653, pp. 296-337, con el título de Los empeños que se ofrecen [BNE R 2277] [M].

Los empeños que se ofrecen, s.a., s.i., Suelta atribuida a Pérez de Montalbán [BL, T.17356] [S].

Los empeños que se ofrecen, s.a., s.i., Suelta atribuida a Pérez de Montalbán [BNE, T/20648] [S1].

De Primero soy yo.

Testimonio base: Sexta parte de comedias del célebre poeta español don Pedro Calderón de la Barca... que publica... don Juan de Vera Tassis..., Francisco Sanz, Madrid, 1683, pp. 137-168. [VT]

BNE, ms. 17.448 22 . [M]

De La estatua de Prometeo.

Testimonio base: BHM, ms. Tea 1-110-12, sin fecha [copiado por Francisco José Sáez de Tejera para el autor-director Manuel de Mosquera]. [BHM] Greer, Margaret Rich, ed., Pedro Calderón de la Barca, La Estatua de Prometeo. A critical edition by Margaret Rich Greer; with a study of the music by Louise K. Stein, Kassel, Reichenberger (Teatro del Siglo de Oro, Ediciones críticas, 7), 1986 [se sirve del ms. de BHM].

De El secreto a voces.

Testimonio base: BNE, ms. Res.117, 59 h.; autógrafo de Calderón (excepto dos hojas), firmado en Madrid el 28 de febrero de 1642. [A] [Hay edición facsímil, con un estudio introductorio y transcripción de José María 
Díez Borque en volumen complementario (Madrid, Biblioteca Nacional

/ Testimonio Editorial, 2000-2001), DB].

HSA, ms. B2616, 52 h. [HSA]

Diferentes, parte 42, Zaragoza 1650, impresas por Juan de Ybar a costa de Pedro Escuer [BL, British Museum 11725.d.10, Difs].

El secreto a voces. 1671, Matheo Cosmerovio. Se usa el ejemplar conservado en Bohemia, en la actual República Checa, en la biblioteca del castillo de Cesky Krumlov, con la signatura 9 I 1823. [VI]

García de la Huerta, Vicente, ed., Theatro Hespañol, Parte tercera, Comedias heroicas, Tomo I, Madrid, Imprenta Real, 1785, pp. 1-198.

Osma, José M. de, ed., El Secreto a voces, comedia de Pedro Calderón de la Barca según el manuscrito autógrafo de la Biblioteca Nacional de Madrid. Bulletin of University of Kansas, XXXIX (1938) (Humanistic Studies VI, núm. 2), Lawrence, University of Kansas Press, 1938).

De Dar tiempo al tiempo.

Testimonio base: Parte diez y siete de comedias nuevas y escogidas de los mejores ingenios de Europa..., Madrid, Melchor Sánchez, 1662, hs. 1-24v. [BNE R22670] [E]

De El mágico prodigioso.

Testimonio base: Parte veinte de comedias varias nunca impresas, compuestas por los mejores ingenios de España..., Madrid, Imprenta Real, 1663, pp. 1-45 [BNE R-22673].

BNE, ms. Vitr. 7-1, 72 h. [hológrafo de Calderón, fechado en 1637].

Calderón de la Barca, El mágico prodigioso, ed. facsímil del manuscrito autógrafo, Suplemento de José María Díez Borque, Madrid, Comunidad de Madrid, Consejería de Educación, 1999.

De Mejor está que estaba.

Testimonio base: Primera parte de Comedias escogidas de los mejores de España, Domingo García y Morrás, a costa de Juan de San Vicente, Madrid, 1652, fols. 108-130 [BNE, R/22654]. [E]

HSA, ms. B 2003, 61 fols. [h]

BNE, T/14790-26 [suelta, sin paginar].

De Fieras afemina amor.

Testimonio base: BNE, T/24101 [suelta, ¿de 1670?].

BNE, ms. 17.031, 125 hs.

BNE, ms. 15.581, 39 hs. 
Wilson, Edward M., ed., Fieras afemina amor. Pedro Calderon de la Barca. A critical edition by Edward M. Wilson, Kassel, Reichenberger (Teatro del Siglo de Oro, Ediciones críticas, 3), 1984.

De Dicha $y$ desdicha del nombre.

Testimonio base: BNE, ms. 14806, 33 hs.

BNE, ms. 16968, 96 hs.

BNE, ms. 17156, 74 hs. [titula Dicha y desecha del hombre].

Parte diez y ocho de Comedias nuevas, escogidas de los mejores ingenios de España, por Gregorio Rodríguez, y a su costa, calle de los Maxareditos, Madrid, 1662, fols. 1-27 [BNE, R/22671].

De Para vencer a amor, querer vencerle.

Testimonio base: Teatro poético en doce comedias nuevas de los mejores ingenios de España, Séptima parte, Domingo García y Morrás, a costa de Domingo de Palacio, Madrid, 1654, fols. 1-24 [BNE R 22660].

BNE, ms. 15614, 63 hs.

ed. impresa en Valencia, 1689, Lorenzo Mesnier, 22 hs. [BNE T 1.032].

\section{EsTUDIOS}

Alcina Franch, J. y Blecua, J. M., Gramática española, Barcelona, Ariel, 1975. Viña Liste, J. M. ${ }^{a}$, "La intervención de Vera Tassis en la Sexta parte de comedias de Calderón (1683) y su valor testimonial», Criticón, 108, 2010, pp. 115-132.

— «La edición vienesa de El secreto a voces de 1671 y su valor textual», [2011, en prensa]. 